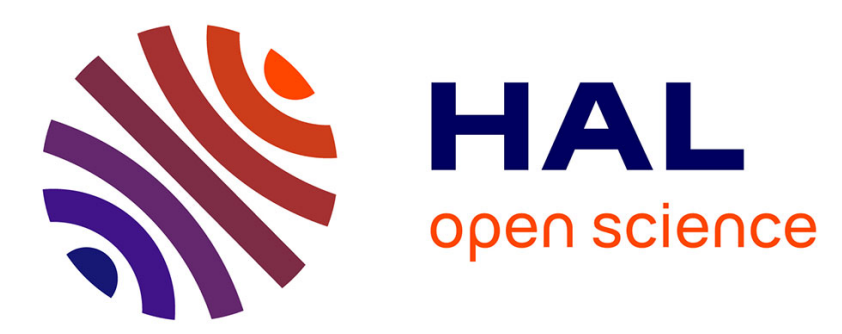

\title{
Modelling Ductile Stable Crack Growth in a C-Mn Steel with Local Approaches
}

Laurent Bauvineau, Hélène Burlet, C. Eripret, André Pineau

\section{To cite this version:}

Laurent Bauvineau, Hélène Burlet, C. Eripret, André Pineau. Modelling Ductile Stable Crack Growth in a C-Mn Steel with Local Approaches. Journal de Physique IV Proceedings, 1996, 06 (C6), pp.C633-C6-42. 10.1051/jp4:1996604 . jpa-00254432

\section{HAL Id: jpa-00254432 https://hal.science/jpa-00254432}

Submitted on 1 Jan 1996

HAL is a multi-disciplinary open access archive for the deposit and dissemination of scientific research documents, whether they are published or not. The documents may come from teaching and research institutions in France or abroad, or from public or private research centers.
L'archive ouverte pluridisciplinaire $\mathbf{H A L}$, est destinée au dépôt et à la diffusion de documents scientifiques de niveau recherche, publiés ou non, émanant des établissements d'enseignement et de recherche français ou étrangers, des laboratoires publics ou privés. 


\title{
Modelling Ductile Stable Crack Growth in a C-Mn Steel with Local Approaches
}

\author{
L. Bauvineau*, H. Burlet*,**, C. Eripret*** and A. Pineau* \\ * Centre des Matériaux, Ecole des Mines de Paris, URA 866 du CNRS, BP. 87, 91003 Evry, France \\ ** CEA, DEM/SGM, 17 rue des Martyrs, 38054 Grenoble cedex 9, France \\ *** EDF-MTC, Direction des Etudes et Recherches, Route de Sens, 77250 Moret-sur-Loing, France
}

\begin{abstract}
J}_{\mathrm{R}}$-resistance curves obtained on a C-Mn steel with different specimens are compared. The experiments confirm a geometrical dependence of the fracture toughness. An attempt is made to explain these results in terms of models derived from the local approach to fracture. Two types of model are presented where the damage is, either uncoupled or coupled to the material behaviour. The uncoupled model with the Tai-Yang approach and the coupled model with the Rousselier potential give results in good agreement with the experiments.
\end{abstract}

\section{INTRODUCTION}

The mechanical integrity of PWR components based on fracture mechanics requires the determination of $\mathrm{J}_{\mathrm{R}}$-curves obtained from laboratory specimens, for example CT or SENB specimens. The original idea was that one unique resistance curve is sufficient to characterize the material. However, there is a growing body of evidence showing that the $\mathbf{J}_{\mathrm{R}}$-curves, especially the tearing modulus, depend on the specimen size, geometry and loading mode. Moreover, this dependency is different from one material to another. Therefore, the application of the $J_{R}$-curves for real structures is questionable. One method to obtain loading and geometry independent material parameters is to model the microscopic processes of ductile damage. This method is called 'local approach'. This analysis was used in particular by Mudry et al. [1]. These authors show, for different stress hardening exponents and when general yielding is reached, effects of specimen size and geometry on the value at crack initiation, $\mathrm{J}_{1 \mathrm{c}}$.

This paper is divided into two main parts. Firstly, we discuss the effect of side grooves and geometrical effects on the $\mathrm{J}_{\mathrm{R}}$-curves of a $\mathrm{C}$-Mn steel. Secondly, we propose two local approaches based on uncoupled models for the prediction of ductile crack initiation (Rice \& Tracey [2] and Tai \& Yang [3-4]) and coupled models (Gurson [5] and Rousselier [6]) for the prediction of not only ductile crack initiation but also crack growth.

\section{MATERIAL AND EXPERIMENTAL PROCEDURES}

\subsection{Material}

A C-Mn steel of PWR secondary piping component with a ferritic-pearlitic microstructure was tested at $300^{\circ} \mathrm{C}$. The distribution of $\mathrm{MnS}$ and $\mathrm{Al}_{2} \mathrm{O}_{3}$ inclusions resulting from the relatively high content in sulfur 
(210ppm, see Table 1) and from the rolling conditions was largely inhomogeneous and formed clusters. The volume fraction of inclusions, $\mathrm{f}_{\mathrm{v}}$, was estimated from the chemical composition [7] :

$$
\mathrm{f}_{\mathrm{v}}=0.054\left[\% \mathrm{~S}-\frac{0.001}{\% \mathrm{Mn}}\right]+0.05 \% \mathrm{O}=0.15 \%
$$

Quantitative metallography was used to measure the inhomogeneity in the distribution of inclusions responsible for the initiation of ductile rupture. This analysis led to a volume fraction of about $0.23 \%$ which is not too far from the above result. The metallographic analysis provided also the distribution and the average distances between the inclusions and the inclusion clusters (see Table 2). In this paper, we take the hypothesis of an uniform repartition. Further work is under progress to account for these distributions.

\begin{tabular}{|c|c|c|c|c|c|c|c|c|c|}
\hline $\mathbf{C}$ & $\mathbf{S i}$ & $\mathbf{M n}$ & $\mathbf{P}$ & $\mathbf{S}$ & $\mathbf{C r}$ & $\mathbf{N i}$ & $\mathbf{O}$ & $\mathbf{A l}$ & $\mathbf{N}$ \\
\hline 0.20 & 0.23 & 0.97 & 0.022 & 0.021 & 0.10 & 0.12 & 0.008 & 0.007 & 0.011 \\
\hline
\end{tabular}

Table 1 : Chemical composition in weight percent.

\begin{tabular}{|c|c|c|}
\hline Plane & $\begin{array}{c}\text { Distance between } \\
\text { inclusions }(\boldsymbol{\mu m})\end{array}$ & $\begin{array}{c}\text { Distance between } \\
\text { clusters }(\boldsymbol{\mu m})\end{array}$ \\
\hline TL & 179 & 1059 \\
\hline LS & 83 & 293 \\
\hline TS & 64 & 220 \\
\hline
\end{tabular}

Table 2 : Average distance between inclusions and clusters.

The mechanical properties and the work-hardening exponent, $n\left(\sigma=K . \varepsilon^{\mathrm{n}}\right)$ measured at $300^{\circ} \mathrm{C}$ in the tangential direction $(\mathrm{T})$ are given in Table 3.

\begin{tabular}{|c|c|c|c|c|}
\hline $\begin{array}{c}\text { YS } \\
(\mathbf{M P a})\end{array}$ & $\begin{array}{c}\text { UTS } \\
(\mathbf{M P a})\end{array}$ & $\begin{array}{c}\text { Elongation } \\
(\%)\end{array}$ & $\begin{array}{c}\text { Reduction } \\
\text { in area (\%) }\end{array}$ & $\mathbf{n}$ \\
\hline 187 & 502 & 25 & 52 & 0.27 \\
\hline
\end{tabular}

Table 3 : Tensile Properties at $300^{\circ} \mathrm{C}$ (T direction).

\subsection{Fracture specimen design}

In order to determine the influence of stress state on the ductility at rupture, tests on axisymmetric notched specimens (AE) were performed. The specimen geometries are shown in Fig. 1. These geometries were retained because they enable us to obtain quasi-homogeneous stress-strain field. Therefore, the variables of the damage model can easily be determined. These specimens were instrumented with a diametral extensometer.

J-resistance curves were established using compact-type (CT) specimens and single edge notched tension (SENT) specimens (Fig. 2). The crack plane was chosen such that the crack propagates along the rolling direction (L) of the plate. Conventional CT specimens with and without $20 \%$ side grooves and $a / W \approx 0.60$ were tested. The SENT specimens had in-plane dimensions of $25 \times 25 \mathrm{~mm}$ with and without $20 \%$ side grooves and $a / W \approx 0.35$. These specimens were tested under clamped conditions which strongly limitate the rotation. Non-conventional CT specimens with $20 \%$ side grooves and a reduced crack length such that $\mathrm{a} / \mathrm{W} \approx 0.30$ were also used. All the specimens have a nominal thickness of $25 \mathrm{~mm}$, except for CT 22.5 $\mathrm{a} / \mathrm{W} \approx 0.30$ where the thickness is $22.5 \mathrm{~mm}$. 

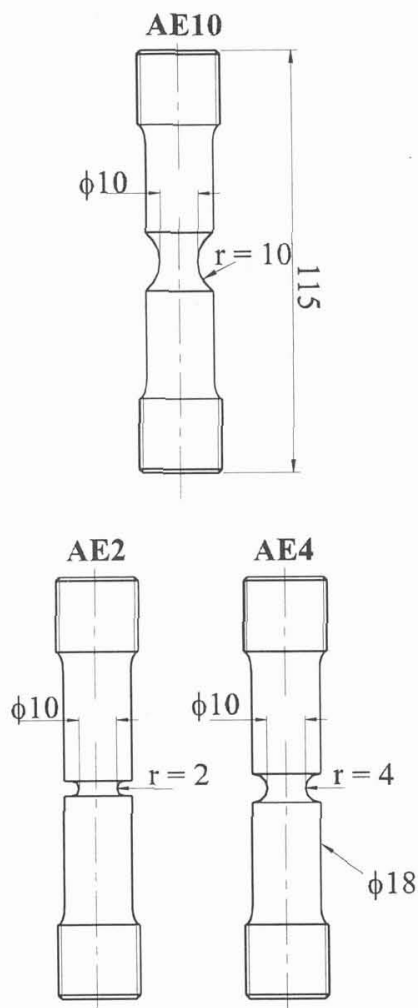

Figure 1 : Axisymmetric notched specimens
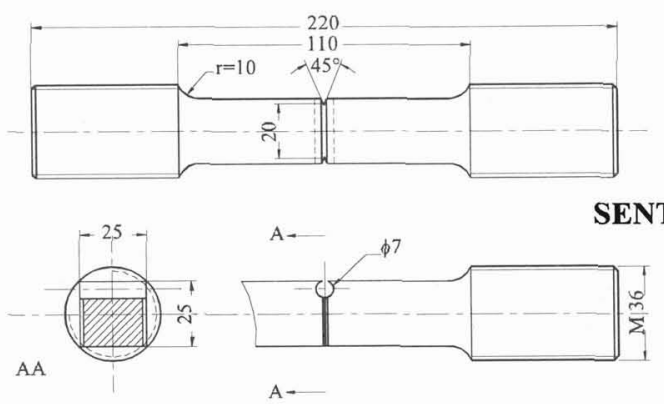

$\mathrm{CT} 22.5 \mathrm{a} / \mathrm{W}=\mathbf{0 . 3 0}$
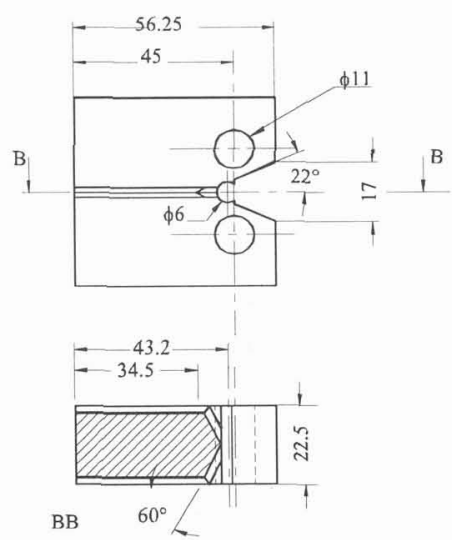

$\mathrm{CT} 25 \mathrm{a} / \mathrm{W}=\mathbf{0 . 6 0}$
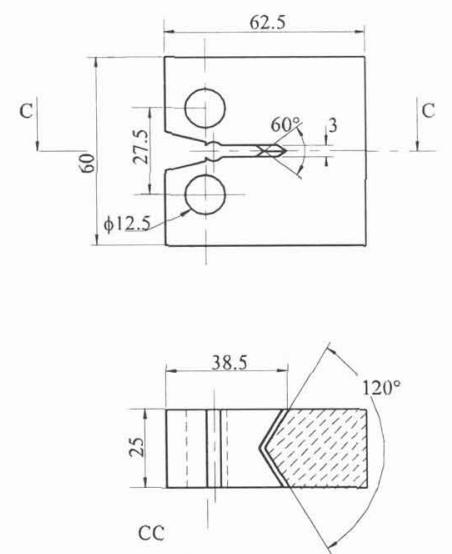

Figure 2 : SENT25 a/W=0.34, CT25 a/W=0.60 and CT22.5 $\mathrm{a} / \mathrm{W}=0.30$

\subsection{Calculation of $\mathbf{J}$}

The J-integral for the CT25 (a/W=0.60) specimens was evaluated following the ASTM E813-89 procedure. For the SENT specimens (with clamped conditions) and CT specimens with small cracks $(\mathrm{a} / \mathrm{W}=0.30)$, the $\mathrm{J}$-integral was estimated from the area $(\mathrm{U})$ under the curve giving the load $(\mathrm{P})$ versus the crack mouth opening displacement $(\delta)$ :

$$
J=\frac{\eta_{\delta} U}{B_{N}\left(W-a_{0}\right)}
$$

where $B_{N}$ is the specimen net thickness and $a_{0}$ is the initial crack length. The $\eta_{\delta}$ coefficient was determined from FEM calculations [8] :

$$
\begin{array}{ll}
\eta_{\delta}^{\mathrm{SENT}}=1+0.084 \mathrm{a} / \mathrm{W}-1.178(\mathrm{a} / \mathrm{W})^{2} & \text { for } 0.1 \leq \mathrm{a} / \mathrm{W} \leq 0.6 \\
\eta_{\delta}^{\mathrm{CT}}=1.255-0.266 \mathrm{a} / \mathrm{W}+4.168(\mathrm{a} / \mathrm{W})^{2} & \text { for } 0.2 \leq \mathrm{a} / \mathrm{W} \leq 0.45
\end{array}
$$

In this study, we found that the $\eta_{\delta}$ coefficient was dependent of the work-hardening exponent (n). This result was also observed by Kirk and Dodds [9] for SENB specimens. The $\eta_{\delta}$ coefficient from Eq. 3 and Eq. 4 are given for $n$ equal to 0.27 .

The crack extension, $\Delta \mathrm{a}$, was measured from direct examinations of the crack surface of the specimens broken at liquid nitrogen temperature after unloading. The $\mathrm{J}_{\mathrm{R}}$-curves were obtained with the multiple specimen technique. 


\section{EXPERIMENTAL RESULTS}

\subsection{Axisymmetric notched specimens}

The ductility at failure $\varepsilon_{\mathrm{r}}$ was calculated from the relation $\varepsilon_{\mathrm{r}}=2 \ln \left(\phi_{0} / \phi_{\mathrm{r}}\right)$, where $\phi_{0}$ is the initial diameter of the minimum section $\left(\phi_{0}=10 \mathrm{~mm}\right)$ and $\phi_{\mathrm{r}}$ the final diameter. The variation of the ductility measured by $\varepsilon_{\mathrm{r}}$ as a function of stress triaxiality ratio, $\sigma_{\mathrm{m}} / \sigma_{\mathrm{eq}}$ at the center of the specimen, determined from FEM calculations is shown in Fig. 3. The scatter of the ductility for a given specimen arises from the shown inhomogenous distribution of the inclusions.

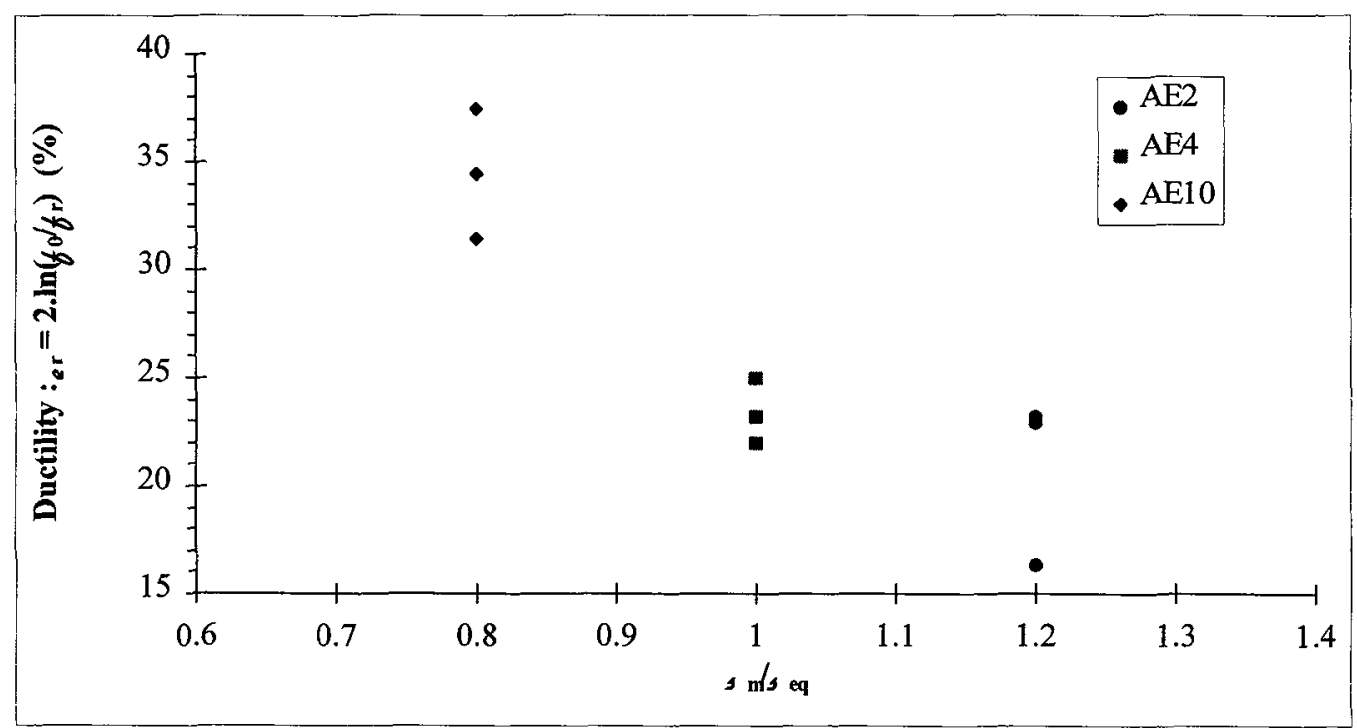

Figure 3 : Ductility of notched specimens.

\subsection{Cracked specimens}

\subsubsection{Side-grooves effect}

The $J_{R}$-curves for CT25 a/W=0.60 and SENT25 a/W=0.35 specimens are compared in Fig. $4 a$. The $J_{1 c}$ values for specimens with side grooves are systematically lower (by $\approx 20 \%$ ) than those of the specimens without side grooves. The slopes $\mathrm{dJ} / \mathrm{da}$ are identical for the CT specimens. But for the SENT geometry, the slope $\mathrm{dJ} / \mathrm{da}$ is higher $(\approx 20 \%)$ for the specimens without side grooves.

\subsubsection{Geometrical effect}

In all cases (with and without side grooves), the $J_{1 \mathrm{c}}$ values are larger in SENT specimens (by $\approx 30 \%$ ) than in CT25 a/W=0.60 specimens (Fig. 4a). The slopes $\mathrm{d} / \mathrm{da}$ are similar except for the SENT specimens without side grooves (see Fig. 4a). In Fig. $\mathbf{4 b}$, the $\mathbf{J}_{\mathbf{l c}}$ values for the different CT-specimens are identical but the slope for the small cracks is lower than the slope measured in the specimens containing long cracks $(\approx 65 \%)$. Therefore, the results for the CT-specimens with long cracks are non-conservative. 


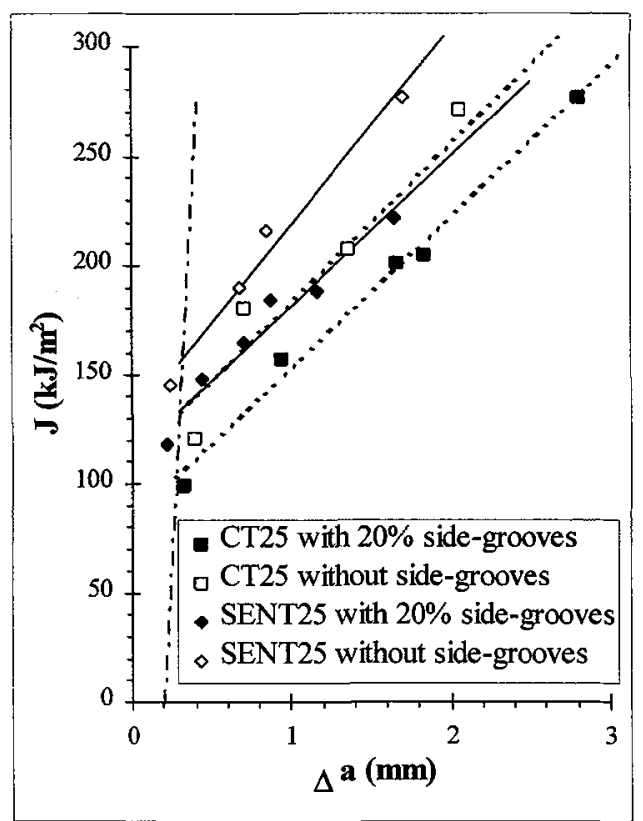

Figure 4a: Geometry and side-grooves effect on $\mathrm{J}_{\mathrm{R}}$-curves for $\mathrm{CT} 25 \mathrm{a} / \mathrm{W} \approx 0.60$ and SENT25 a/W $\approx 0.35$

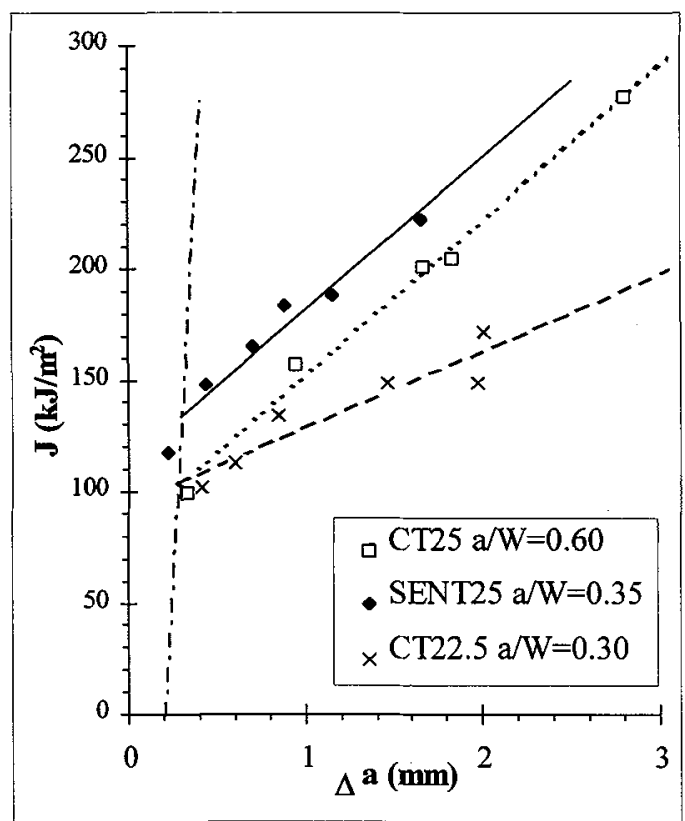

Figure 4b: Geometry effect on $\mathrm{J}_{\mathrm{R}}$-curves for crack specimens with $20 \%$ sidegrooves

\section{NUMERICAL ANALYSIS}

In the present study, we analyse only the case of specimens with side-grooves for which $2 \mathrm{D}$ calculations under plane strain conditions can be used. A number of 3D calculations were also made (see [10]). From these calculations, it was found that the stress triaxiality ratio, at crack initiation, is about 1.7 for SENT specimens, 3.0 for CT specimens with long cracks and 4.0 for CT specimens with small cracks. These results can explain the observed variations of $\mathrm{J}_{1 \mathrm{c}}$ values through models based on the local approach to fracture.

\subsection{Uncoupled models}

The hypothesis of this approach is the damage does not alter the behaviour of the material. The damage in the specimens is calculated after a FEM calculation in post-processing. The damage is calculated with two approaches : based on cavity growth or on continuum damage mechanics theory.

\subsubsection{Model based on critical cavity growth}

The growth of cavities initiated from inclusions is assumed to obey the Rice and Tracey [2] or Huang [11] equations :

$$
\begin{aligned}
& \text { Rice and Tracey }: \ln \left(\frac{\mathrm{R}}{\mathrm{R}_{0}}\right)_{\mathrm{c}}=\int_{\varepsilon_{0}}^{\varepsilon_{\mathrm{r}}} 0.283 \exp \left(\frac{3}{2} \frac{\sigma_{\mathrm{m}}}{\sigma_{\mathrm{eq}}}\right) \mathrm{d} \varepsilon_{\mathrm{eq}}^{\mathrm{p}} \\
& \text { Huang : } \quad \ln \left(\frac{\mathrm{R}}{\mathrm{R}_{0}}\right)_{\mathrm{c}}=\int_{\varepsilon_{0}}^{\varepsilon_{\mathrm{r}}} 0.427\left(\frac{\sigma_{\mathrm{m}}}{\sigma_{\mathrm{eq}}}\right)^{1 / 4} \exp \left(\frac{3}{2} \frac{\sigma_{\mathrm{m}}}{\sigma_{\mathrm{eq}}}\right) \mathrm{d} \varepsilon_{\mathrm{eq}}^{\mathrm{p}} \quad \text { if } \sigma_{\mathrm{m}} / \sigma_{\mathrm{eq}} \leq 1 \\
& \ln \left(\frac{R}{R_{0}}\right)_{c}=\int_{\varepsilon_{n}}^{\varepsilon_{\mathrm{r}}} 0.427 \exp \left(\frac{3}{2} \frac{\sigma_{\mathrm{m}}}{\sigma_{e q}}\right) d \varepsilon_{\mathrm{eq}}^{\mathrm{p}} \quad \text { if } \sigma_{\mathrm{m}} / \sigma_{\mathrm{eq}}>1
\end{aligned}
$$


where $R$ is the actual size of the cavities and $R_{0}$ their initial size. The initial strain $\varepsilon_{0}$ corresponding to the nucleation of cavities is assumed to be equal to zero. In the above equations, $\varepsilon_{\mathrm{r}}$ represents the strain to failure.

\subsubsection{Model based on continuum damage theory.}

Tai and Yang [3-4] introduced an approach based on the Lemaitre's continuum damage mechanics model [12] to describe ductile fracture. The damage parameter, denoted $V_{D}$, is defined for a perfectly plastic material by :

$$
\left(V_{D}\right)_{c}=\int_{\varepsilon_{0}}^{\varepsilon_{\mathrm{r}}} F\left(\sigma_{\mathrm{m}} / \sigma_{\mathrm{eq}}\right) \mathrm{d} \varepsilon_{\mathrm{eq}}^{\mathrm{p}} \quad \text { with } \mathrm{F}\left(\frac{\sigma_{\mathrm{m}}}{\sigma_{\mathrm{eq}}}\right)=\frac{2}{3}(1+\nu)+3(1-2 \nu)\left(\frac{\sigma_{\mathrm{m}}}{\sigma_{\mathrm{eq}}}\right)^{2}
$$

In our material, the work hardening exponent is large $(n \approx 0.27)$. We have therefore to use the original expression of $V_{D}$ [3]. This second damage parameter, denoted $V_{D M}$, is expressed as :

$$
\left(V_{\mathrm{DM}}\right)_{\mathrm{c}}=\int_{\varepsilon_{0}}^{\varepsilon_{\mathrm{r}}} \mathrm{F}\left(\sigma_{\mathrm{m}} / \sigma_{\mathrm{eq}}\right)\left(\varepsilon_{\mathrm{eq}}^{\mathrm{p}}\right)^{2 \mathrm{n}} \mathrm{d} \varepsilon_{\mathrm{eq}}^{\mathrm{p}}
$$

\subsubsection{Identification of the parameters.}

The fracture criterion has two independent parameters. The first one is the critical damage $\left(R / R_{0}\right)_{c},\left(V_{D}\right)_{c}$ or $\left(\mathrm{V}_{\mathrm{DM}}\right)_{\mathrm{c}}$; the second one is the process zone size ahead of the crack tip. According to the methodology of the local approach [1], the critical damage has been assessed from tests on notched tensile specimens. In these specimens, the mesh size is not an important parameter since stress and strain gradients are low.

\subsubsection{Results}

The critical cavity growth ratio $\left(R / R_{0}\right)_{c}$, and the critical damage $\left(V_{D}\right)_{c}$ or $\left(V_{D M}\right)_{c}$ for the present C-Mn steel were found approximately constant and independant of stress triaxiality ratio (see Fig. $5 \mathbf{a}-\mathbf{5 b}$ ). The second parameter is the mesh size $(\lambda)$ at the crack-tip. This parameter is fitted from the calculations performed on $\mathrm{CT} 25 \mathrm{a} / \mathrm{W} \approx 0.60$-specimens to simulate crack initiation. The values of $\lambda,\left(\mathrm{R} / \mathrm{R}_{0}\right)_{\mathrm{c}},\left(\mathrm{V}_{\mathrm{D}}\right)_{\mathrm{c}}$ or $\left(\mathrm{V}_{\mathrm{DM}}\right)_{\mathrm{c}}$ are then used to predict crack initiation $\left(\mathrm{J}_{1 \mathrm{c}}\right)$ for SENT25 and CT22.5 a/W $=0.30$ specimens. Full details can be found elsewhere [8].
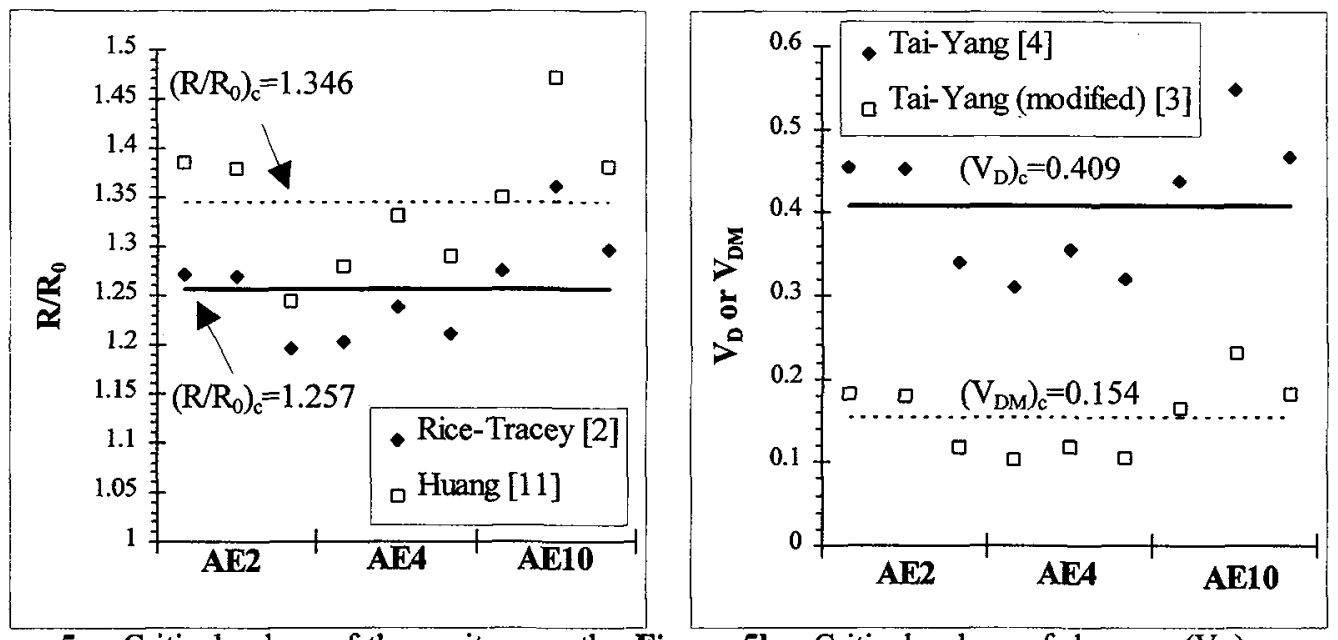

Figure 5a : Critical values of the cavity growth Figure 5b: Critical values of damage $\left(\mathrm{V}_{\mathrm{D}}\right)_{\mathrm{c}}$ or $\left(\mathrm{R} / \mathrm{R}_{0}\right)_{\mathrm{c}}$ for different notched specimens.

$\left(\mathrm{V}_{\mathrm{DM}}\right)_{\mathrm{c}}$ for different notched specimens. 
The predictions from models are presented in Fig. 6 and in Table 4. The results show that the models based on cavity growth tend to predict dependencies of $J_{1 c}$ values much larger than those observed : $\left(\mathrm{J}_{1 \mathrm{c}}{ }^{\mathrm{SENT}}\right)^{\text {model }} \approx 300 \mathrm{~kJ} / \mathrm{m}^{2}$ as compared to $\left(\mathrm{J}_{1 \mathrm{c}}\right)^{\text {exp. }}=130 \mathrm{~kJ} / \mathrm{m}^{2}$ and $\left(\mathrm{J}_{1 \mathrm{c}}{ }^{\mathrm{CT}} \text { a/ } / \mathrm{W}=0.32\right)^{\mathrm{model}} \approx 50 \mathrm{~kJ} / \mathrm{m}^{2}$ for $\left(J_{1 c}\right)^{\text {exp }}=100 \mathrm{~kJ} / \mathrm{m}^{2}$. For the model based on continuum damage mechanics the results are in better agreement with the experimental results. Moreover, the element size is similar to the average distance between inclusions clusters in the propagation LS plane when the damage $V_{D}$ is introduced and to the average distance between inclusions in the same plane when the damage $\mathrm{V}_{\mathrm{DM}}$ is used.

It should be noted that these models can only be easily used to describe crack initiation and not crack growth. This is the reason why coupled models which are able to describe both stages of ductile fracture were also used.

\begin{tabular}{|c|c|c|c|c|c|}
\hline & \multicolumn{3}{|c|}{$J_{1 c}\left(k J / m^{2}\right)$} & & \\
\hline Specimens & $\begin{array}{l}\text { CT25-TL } \\
\mathrm{a} / \mathrm{W} \approx 0.60\end{array}$ & $\begin{array}{c}\text { CT22.5-TL } \\
\mathrm{a} / \mathrm{W} \approx 0.30\end{array}$ & $\begin{array}{c}\text { SENT25-TL } \\
\text { a/W } \approx 0.34\end{array}$ & & \\
\hline Experiments & 101 & 101 & 133 & $\lambda(\mu \mathrm{m})$ & $\begin{array}{c}\left(\mathbf{R} / \mathbf{R}_{\mathbf{0}}\right)_{\mathbf{c}} \\
\left(\mathbf{V}_{\mathbf{D}}\right)_{\mathrm{c}}-\left(\mathbf{V}_{\mathbf{D M}}\right)_{\mathrm{c}}\end{array}$ \\
\hline Rice-Tracey & 104 & 52 & 313 & 700 & 1.257 \\
\hline Huang & 101 & 51 & 306 & 800 & 1.346 \\
\hline Tai-Yang & 101 & 103 & 150 & 250 & 0.409 \\
\hline Tai-Yang (modified) & 100 & 95 & 120 & 120 & 0.154 \\
\hline
\end{tabular}

Table 4 : Models predictions from models with the element sizes and the critical values.

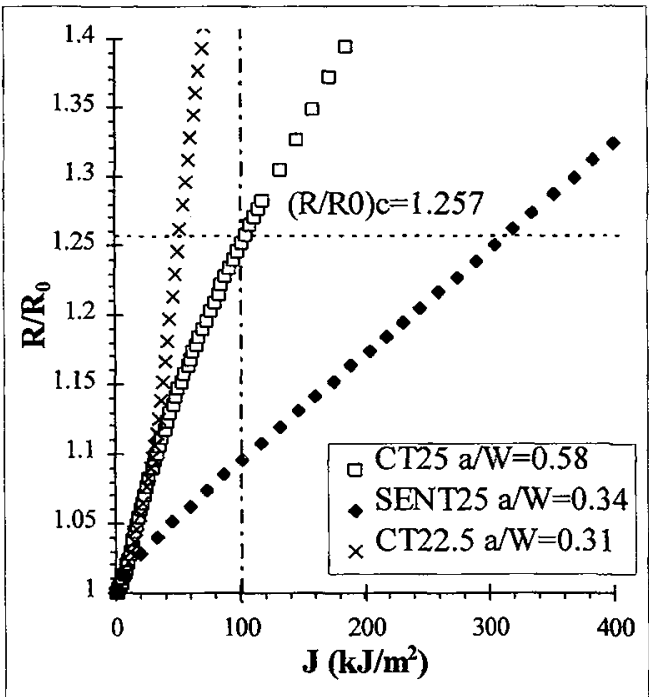

Figure 6a : Variations of the cavity growth $\left(R / R_{0}\right)$ for different specimens. The $J_{1 c}$ value of the specimens is defined by the intersection of $\left(R / R_{0}\right)_{c}$ value measured on notched specimens with calculated $\left(R / R_{0}\right)$ values.

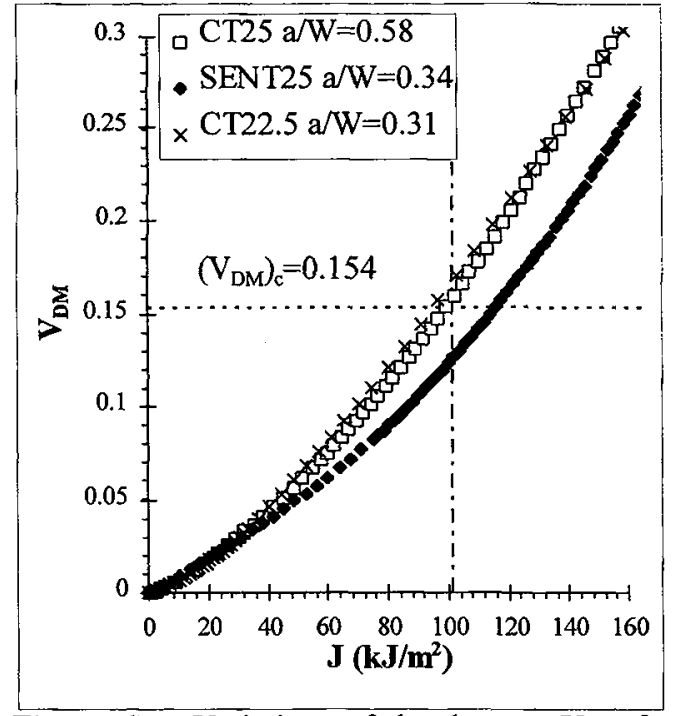

igure 6b : Variations of the damage $V_{D M}$ for different specimens. The $J_{1 c}$ value of the specimens is defined by the intersection of $\left(V_{D M}\right)_{c}$ value determined on notched specimens with calculated $V_{D M}$ values. 


\subsection{Coupled models}

Ductile fracture is generally considered as an instability due to the softening effect induced by cavity growth. This softening effect on the yield conditions was introduced by Gurson [5] and also by Rousselier [6]. This coupling between damage and constitutive equation is an excellent tool to simulate crack propagation and $\mathrm{J}_{\mathrm{R}}$-curves.

\subsubsection{Gurson potential}

The porous potential $\Phi$ introduced by Gurson and modified by Tvergaard and Needleman [13] is given by :

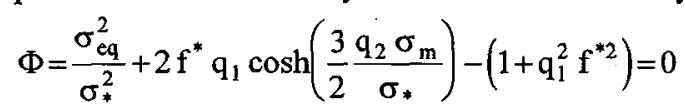

where $\sigma_{*}$ is the equivalent stress of an ideal material without damage, $\sigma_{\mathrm{eq}}$ and $\sigma_{\mathrm{m}}$ are macroscopic stresses (flow and hydrostatic). The parameters $q_{1}$ and $q_{2}$ are numerical constants. $f^{*}$ is an accelerating function of the porosity $f$. Initially $f^{*}=f$, but, at some critical volume fraction, $f_{c}, f^{*}$ is written as $f^{*}=f_{c}+\delta$.(f$\left.f_{c}\right)$ where $\delta$ is an accelerating factor. The growth rate of the void volume fraction is given by : $\dot{f}=(\dot{f})_{\text {growth }}$ with $(\dot{\mathrm{f}})_{\text {growth }}=(1-\mathrm{f}) \cdot \mathrm{d} \dot{\varepsilon}_{\mathrm{ii}}$. The nucleation of the cavities is assumed to take place instantaneously.

\subsubsection{Rousselier potential}

The Rousselier model [6] defines the following porous plastic potential $\Phi$ :

$$
\Phi=\frac{\sigma_{\mathrm{eq}}}{(1-\mathrm{f}) \sigma_{*}}+\frac{\sigma_{1}}{\sigma_{*}} \mathrm{f} D \exp \left(\frac{\sigma_{\mathrm{m}}}{(1-\mathrm{f}) \sigma_{1}}\right)-1=0
$$

where $\mathrm{D}$ and $\sigma_{1}$ are material parameters.

\subsubsection{Identification of the parameters}

The initial volume fraction of cavities, $f_{0}$, is deduced from the volume fraction of inclusion, $f_{v}$, i.e., $\mathrm{f}_{0}=\mathrm{f}_{\mathrm{v}}=0.20 \%$. The parameters of the Gurson and Rousselier models are fitted from the results on CT25 $\mathrm{a} / \mathrm{W}=0.60$ specimens in order to simulate correctly the crack propagation behaviour. In the Gurson model, we used the conventional values of $q_{1}$ and $q_{2}$ parameters : $q_{1}=1.5$ and $q_{2}=1$. The $f_{c}$ value is calculated as [14]: $f_{c}=f_{0} \cdot\left(R / R_{0}\right)_{c}{ }^{3}=0.40 \%$ (with $\left(R / R_{0}\right)_{c}{ }^{\text {Ricestracey }}=1.257$ ). The identifications led to $: \delta=2$ and $\lambda=200 \mu \mathrm{m}$ for the Gurson model and $\mathrm{D}=2, \sigma_{1}=240 \mathrm{MPa}$ with $\lambda=200 \mu \mathrm{m}$ for the Rousselier model.

\subsubsection{Results}

The numerical and experimental results obtained on CT and SENT side-grooved specimens are shown in Fig. 7. In this figure, it is observed that the Gurson model (Fig. 7a) tends to overestimate the experimental geometrical dependence. In particular, the predicted values of the J- $\triangle \mathrm{a}$ curve for SENT specimens are much larger than those which were measured. On the other hand, better results are obtained with the Rousselier potential (Fig. 7b), except for the CT specimens with small cracks. This situation is likely related to the appearance of a bifurcation in the crack path shown numerically. The calculated crack growth takes place away from the center plane. This behaviour is related to the plastic zone observed in this specific geometry since the limit load is reached when the plastic zones initiated from the crack tip and from the CT hole are touching each other.

The calculated and experimental loading curves for notched tensile specimens are compared in Fig. 8. These curves were calculated with the same parameters are those used for the numerical simulation of the 


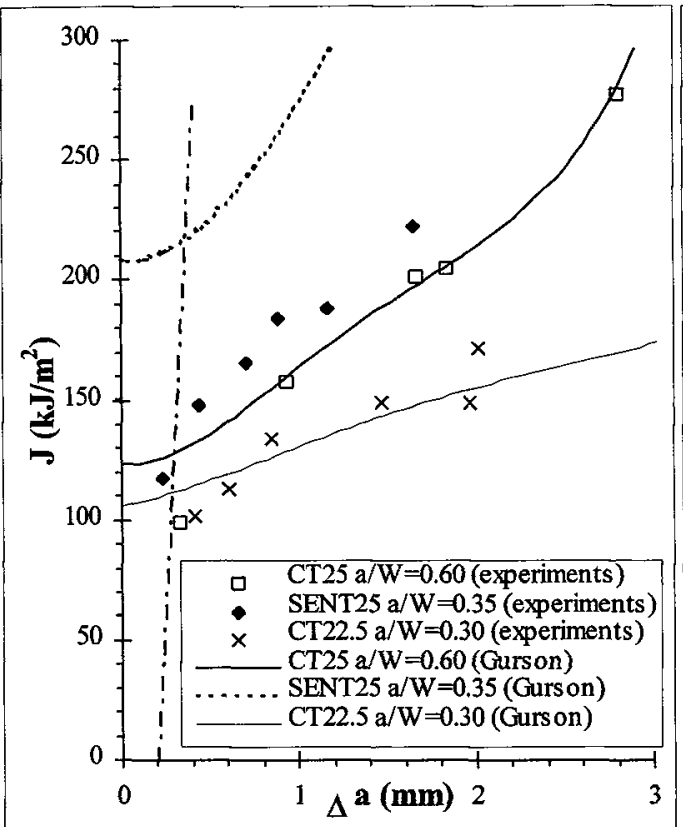

Figure 7a : Comparison between calculated (with Gurson model) and experimental results (for side-grooved specimens).

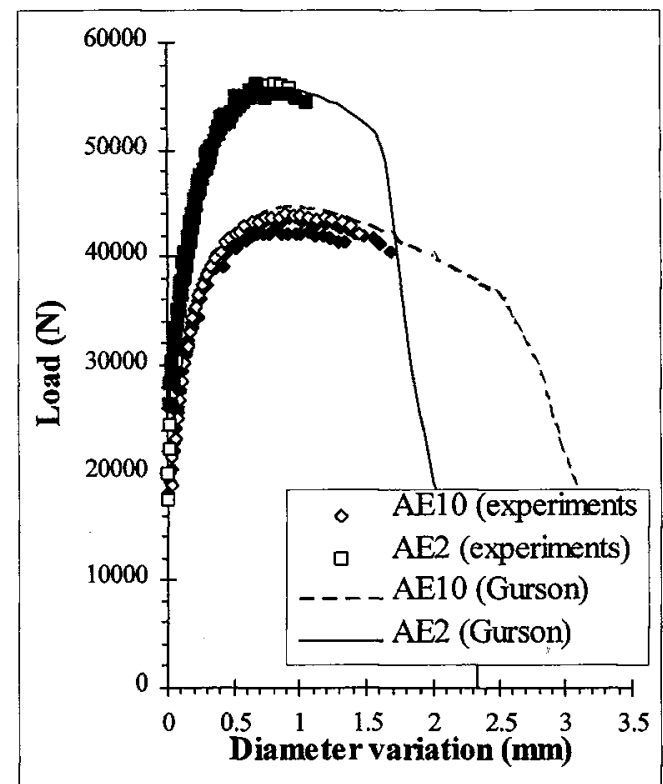

Figure 8a : Comparison between calculated (with Gurson model) and experimental results (for notched tensile specimens).

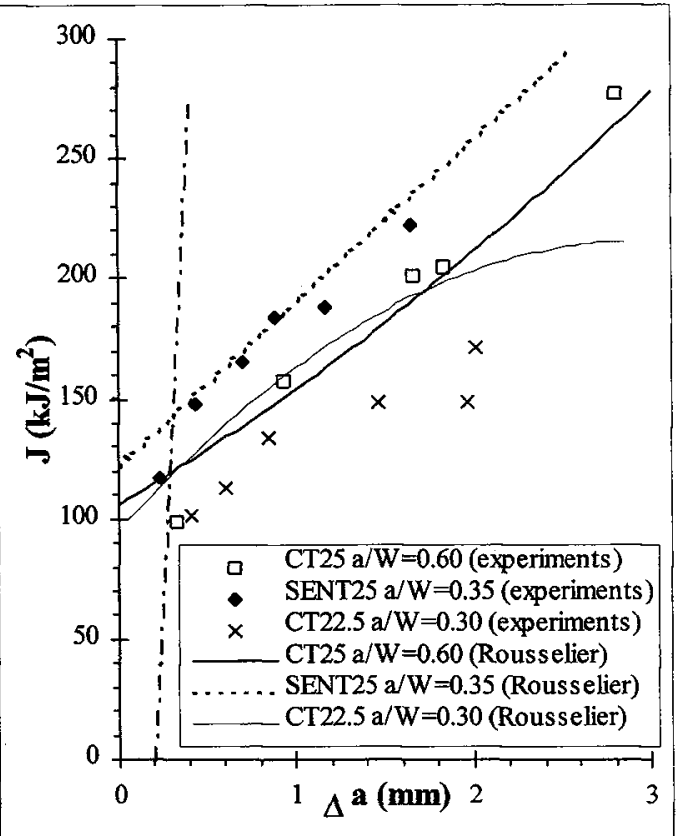

igure $7 \mathrm{~b}$ : Comparison between calculated (with Rousselier model) and experimental results (for side-grooved specimens).

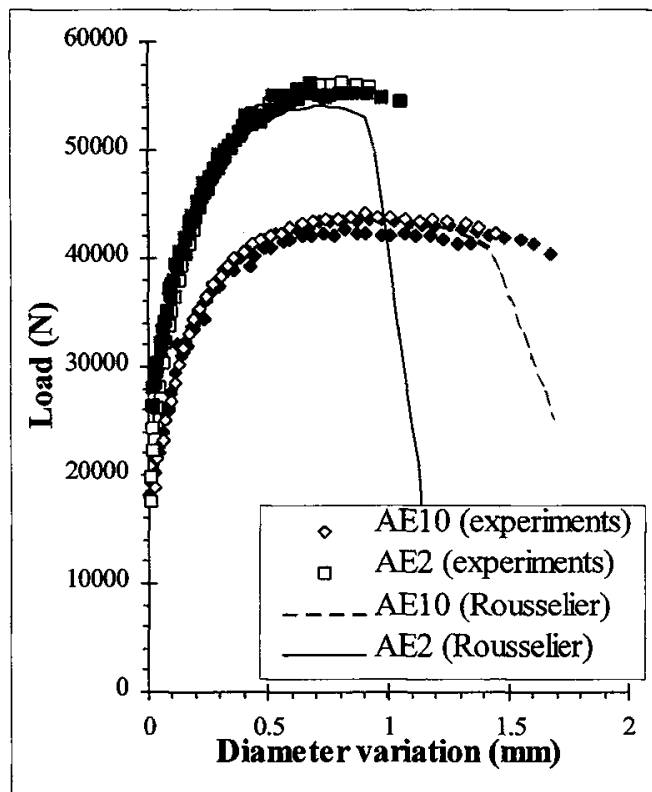

Figure 8b : Comparison between calculated (with Rousselier model) and experimental results (for notched tensile specimens). 
cracked specimens. Fig. 8a shows that the Gurson model tends to overestimate the strain to failure as already observed for the SENT specimens with the lower stress triaxiality ratio. The agreement between the experiments and the calculations is better with the Rousselier model.

\section{CONCLUSIONS}

Tests carried out on different specimens confirm that $J_{R}$-curves are dependent on specimen geometry. In particular the values of $J$ are found to be lower in CT type specimens than in SENT specimens. For the case of CT specimens with small crack $(a / W \approx 0.30)$, the $J$ values are lower than $C T$ specimen with large crack $(\mathrm{a} / \mathrm{W} \approx 0.60)$.

Two models based on the local approach for fracture analysis have been used. The uncoupled model with the Tai and Yang approach allows a good agreement with the experimental results for the $J_{1 \mathrm{c}}$ values. But, the model based on critical cavity growth with a uniform distribution of inclusions is shown to be unable to fully explain the observed geometrical dependence. The model based on Rousselier potential gives results in better agreement with the experiments than the Gurson model.

\section{REFERENCES}

[1] Mudry F, di Rienzo F., Pineau A., ASTM STP 995, J. D. Landes et al. (ed.), 1989, pp. 24-39.

[2] Rice J. R., Tracey D. M., J. Mech. and Phys. of Sol., Vol. 17, 1969, pp. 201-217.

[3] Tai W. H., Yang B. X., Eng. Fract. Mech., Vol. 25, No. 3, 1986, pp. 377-384.

[4] Tai W. H., Yang B. X., Eng. Fract. Mech., Vol. 27, No. 4, 1987, pp. 371-378.

[5] Gurson A. L., J. Engng. Mat. Mech., Vol. 99, 1977, pp. 2-15.

[6] Rousselier G., Nucl. Eng. and Design, Vol. 105, 1987, pp. 97-111.

[7] Franklin A. G., J. of The Iron and Steel Institute, Feb. 1969, pp. 181-186.

[8] Bauvineau L., Burlet H., Pineau A., internal report EDF-DER/ARMINES, $n^{\circ}$ T42L33/7DO225 RNE450, Février 1996.

[9] Kirk M. T., Dodds R. H., Proceedings of the TWI/EWI/IS int. Conf. on Shallow Crack Fract. Mech., paper 2, Sep. 1992.

[10] Bauvineau L., Bethmont M., Burlet H., Pineau A., Proceedings of the ECF11-Poitiers, 3-6 september 1996.

[11] Huang Y., Transactions of the ASME, Vol. 58, Dec. 1991, pp. 1084-1086.

[12] Lemaitre J., J. Engng. Mater. Technol., Vol. 107, 1985, pp. 83-89.

[13] Tvergaard V., Needleman A., Acta Metall., Vol. 32, 1984, pp.157.

[14] Mudry F., 'Etude de la rupture ductile et de la rupture par clivage d'aciers faiblement alliés', Thesis, 1982. 